\title{
Farklı Isınma Protokollerinin Eklem Hareket Genişliği, Sıçrama ve Sprint Performansına Etkisi
}

\author{
DOI: 10.26466/opus.574260
}

\author{
Tülin Atan* \\ *Doç. Dr, Ondokuz Mayıs Üniversitesi, Yaşar Doğu Spor Bilimleri Fakültesi, Samsun / Türkiye \\ E-Posta: takman@omu.edu.tr \\ ORCID: 0000-0001-5660-8910
}

*

\begin{abstract}
Öz
Çalışma, uygulanan ü̧ farklı ısınma çeşidinin eklem hareket genişliği, sıçrama ve sprint performansı üzerine etkisinin incelenmesi amacıyla yapıldı. Çalışmaya Spor Bilimleri Fakültesinde öğrenim gören 30 erkek öğrenci katıldı (yaş; 20,15 $\pm 2,71$ yll). Tüm sporculara, rastgele sirada ve ard arda olmayan günlerde sadece jogging (J), jogging+dinamik germe (JD) ve jogging+statik germe (JS) egzersizlerini içeren farklı üç ısınma programı uygulandi. Sporcular her protokolden sonra kalça fleksiyonu, dikey sıçrama testi ve 30 metre sprint testini gerçekleştirmişlerdir. Isınma yöntemleri tekrarlı ölçümlerde ANOVA ve post-hoc yöntemleri ile karşılaştırıldl. Kalça fleksiyon değerinin JD ve JS germe sonrasında, J sonrasına göre istatistiksel olarak daha yüksek olduğu tespit edildi $(p<0.01)$. J ve JD ısınma protokolü sonrası ölçülen sıçrama yüksekliği değerlerinin, JS ısınma sonrası ölçülen değerlere göre istatistiksel olarak anlamlı düzeyde daha yüksek olduğu tespit edildi (p<0.05). $30 \mathrm{~m}$ sprint süresinin ise JS protokolü ile ısınma gerçekleştirildiğinde, J ve JD protokolü ile ısınmaya oranla istatistiksel oranda daha uzun olduğu görüldü $(p<0,05)$. Sonuç olarak deneklere uygulanan üç farklı ısınma protokolünden JD ve JS ısınma protokolü eklem hareket genişliği değerleri üzerinde J'ye göre daha etkilidir. Dolayısıyla eklem hareket genişliğinin önemli olduğu spor branşlarında hem sakatlanmayı en aza indirmek hem de yüksek performans sağlamak için mutlaka germe çalısmalarının yapılması gerekir. Ancak statik germe uygulamaları sporcuların sıçrama ve sürat performansların dü̧̈ürmektedir. Bunun önüne geçmek için ise bu tür aktivitelerden önce dinamik germenin yapılması önerilmektedir.
\end{abstract}

Anahtar Kelimeler: Isınma, sıçrama, sprint, eklem hareket genişliği 


\title{
Effect of Different Warm-Up Protocols on Joint Range of Motion, Jumping and Sprint Performance
}

\begin{abstract}
The study was carried out to investigate the effect of three different warming types on joint range of motion, jumping and sprint performance. 30 male students from the Faculty of Sport Sciences attended the study (age; $20.15 \pm 2.71$ years). Three different warm-up programs including jogging (J), jogging + dynamic stretching (JD) and jogging + static stretching (JS) exercises were applied to all athletes in random order on non-consecutive days. Then hip flexion, vertical jump test and 30 meter sprint test values were taken respectively. Repeated measures and post-hoc tests were used for statistical analysis. Hip flex value was significantly higher after JD and JS stretching than J ( $p<0.05)$. The jumping height values measured after the J and JD warming protocol were found to be statistically higher than those measured after the JS warming $(p<0.05) .30 \mathrm{~m}$ sprint time when warming performed with JS protocol was found to be longer, compared to warming with J and JD protocol in statistical ratio ( $p$ 0.05). As a result, JD and JS warming protocol are more effective than J on joint range of motion from three different warming protocols. The jump height and $30 \mathrm{~m}$ sprint performance are lower in JS protocol than in J and JS protocols. Static stretching applications reduce jumping and sprint performance of athletes.
\end{abstract}

Keywords: Warm-up, jump, sprint, joint range of motion 


\section{Giriş}

Genel olarak günlük standart aktivitelere oranla sportif antrenmanlar daha üst düzey eforlardır. Bu eforlar organizmada standartların üzerinde fizyolojik ve psikolojik tepkiler oluşturur. Bu nedenle antrenman öncesinde ön yüklenmeler yapılarak organizma aşamalı olarak yüksek şiddetle efora hazırlanır (Çakıroğlu, 1997). Bazı fizyolog, sporcu ve antrenöre göre 1sınma tamamen kişiyi yapacağı işe mental (psikolojik) olarak hazırlarken bazılarına göre ısınma sporcunun dolaşım sisteminin çalışmanın temposuna hazırlamak ve kas-iskelet sistemini sakatlamaya karşı koymak amacı taşır (Açıkada ve Ergen,1990).

Isınma çalışmalarında sporcunun bireysel özelliklerine, eğitim durumlarına, profesyonellik özelliklerine ve antrenman durumlarına göre yoğunluk ve hacim belirlenerek çalışılmalıdır. Yoğun bir ısınma süresi antrenmansız sporcularda yorgunluk meydana getirir ve yapacağ olumsuz yönde etkiler (Karabina ve Pirselimoğlu, 2017).

Sporda ihtiyaç duyulan en önemli temel motorik özelliklerden olan sürat, çabuk hareket etme veya yer değiştirme kapasitesidir. Mekaniksel açıdan sürat, mesafe ve zaman arasındaki oranla ifade edilir. Sürat kavramı üç elementle doğrudan ilişkilidir; Reaksiyon zamanı, bir zaman biriminde hareketin sıklığı ve belli bir mesafe süratidir. Bu faktörler arasındaki korelasyon sürate ihtiyaç duyulan bir egzersiz performansının değerlendirilmesinde kişiye yardımcı olur (Ziyagil ve ark.,1994). Sürati etkileyen diş faktörlerin arasında iyi bir ısınma ile birlikte; streching, antrenman şiddeti, iklim, yorgunluk, dinlenme, beslenme, sağlık ve sakatlıklar gibi faktörlerde sürati etkilemektedir (Sevim, 1997).

Esnekliğin, eklem hareketliliği, sağlık ve atletik performansın gelişiminde etkin rolü vardır. Düzenli olarak yapılan streching egzersizleri (haftada 2 ila 5 gün ve 15 ile 60 dakika) esnekliği birkaç haftada geliştirir (Fox ve ark., 1999). Esnekliği artırmak için verilen germe egzersizleri birçok sporcunun hem antrenman programlarında hem de isınma aktivitelerinde yer almaktadır.

Aktiviteler öncesi en önemli kriter olarak germe egzersizlerinin yaygın olarak kullanılması ve kabulüne rağmen, iddia edilen yararları ki bunlar performans üzerine ve yaralanmalarının önlenmesi üzerine olan yararlarıdır, birçok araştırmada tartışma konusu olmuştur. Son araştır- 
malar, akut germenin maksimal performans üzerine olumsuz etkisi olduğunu rapor etmişlerdir (Nelson ve ark., 2005a; Çoknaz ve ark., 2008). Buradan yola çıkarak bu çalışmanın amacı J, JD ve JS ısınma protokollerinin esneklik, dikey sıçrama ve sprint süresine etkisini incelemektedir.

\section{Yöntem}

Çalışmaya Samsun Ondokuz Mayıs Üniversitesi Spor Bilimleri Fakülte'sinde öğrenim gören 30 erkek öğrenci gönüllü olarak katıldı. Tüm sporculara, ard arda olmayan günlerde jogging ve jogging+dinamik germe ve jogging+statik germe egzersizlerini içeren farklı üç 1sınma protokolü uygulandı:

Jogging (J) ile 1sınma yapılan günde, denekler ortalama 120 atım/dk kalp atım hızında 10dk koştu ve $1 \mathrm{dk}$ yürüyerek dinlenme gerçekleştirdikten sonra performans testleri gerçekleştirildi.

Jogging+statik germe (JS) Protokolü: Denekler, ortalama 120 atım/dk kalp atım hızında $5 \mathrm{dk}$ koştuktan sonra $5 \mathrm{dk}$ boyunca statik germe yaptı. 5 farklı hareketten oluşan statik germede, 1 hareket 1 dakika sürmüştür. Harekete başlanmış ve 20sn hareket devam etmiş, 10 sn dinlendikten sonra aynı harekete 20 sn daha devam edilmiş ve 10 sn dinlenme aralığ 1 verildikten sonra diğer harekete geçilmiştir. Statik germe uygulamaları yavaşça (aktif germe), gergin bir duyarlılık noktasında (ağrı eşiğinde), uygulanmıştır. Statik germe uygulamaları Hamstring, Quadriseps, Calf, Adductor ve kalça rotator kas gruplarına yönelik gerçekleştirilmiştir (Alter, 1988). Denekler $1 \mathrm{dk}$ yürüyerek dinlenme gerçekleştirdikten sonra performans testleri gerçekleştirildi.

Jogging+dinamik germe (JD) Protokolü :Denekler, ortalama 120 atım/dk kalp atım hızında $5 \mathrm{dk}$ koştuktan sonra $5 \mathrm{dk}$ boyunca dinamik germe yaptı. 5 farklı hareketten oluşan dinamik egzersizlerde, 1 hareket 1 dakika sürmüştür. 15m'lik çizginin başlangıcında harekete başlanmış, 20 sn hareket devam etmiş bu arada çizginin sonuna gelinmiş ve çizgide 10 sn dinlendikten sonra geri dönülerek aynı hareket tekrar edilmiştir. Başlangıç çizgisine geri dönüldüğünde 10 sn dinlendikten sonra 2. hare- 
kete geçilerek 5 farklı hareket bu şekilde uygulanmıştır (Çolak, ve Çetin, 2010). Denekler $1 \mathrm{dk}$ yürüyerek dinlenme gerçekleştirdikten sonra performans testleri gerçekleştirildi.

\section{Dinamik germe egzersizleri;}

1. Dizleri yukarı çekerek yürüme; Yürürken dizler mümkün oldukça göğse doğru çekilirken ayak parmak uçlarında yukarıya doğru yükselerek kollarla en yüksek noktaya ulaşılmaya çalışılır. Her adım hareketinde kollar tam daire çizerek çevrilir.

2. Bacaklar düz pozisyonda askeri yürüyüş; Her iki kol vücudun önünde öne doğru uzatılmış vaziyette yürürken, bacaklar bükülmeden öne doğru uzanmış olan ele doğru kaldırılır. Diğer bacakla aynı hareketi tekrarlamadan önce başlangıç pozisyonuna gelinir.

3. Geriye doğru hamle yürüyüşü; Her bacak en fazla açılabildiği kadar geriye arkaya doğru sağ ve sol adım alınarak yürünür.

4. Ayak topuklarını kalçaya değdirerek yürüme; ileriye doğru hareket ederken ayak topukları hızlı ve çabuk bir şekilde kalçaya değdirilerek yürüme yapılır.

5. Yana doğru kayma adımlarıyla yürüme; Ayakları çapraz yapmadan çabuk bir şekilde yana doğru kayma adımları ile yürüme yapilır.

Performans Ölçümleri: Isınma protokollerinden sonra kalça fleksiyonu ölçümü, dikey sıçrama ölçümü ve son olarak 30 metre sprint süresi ölçümü yapıldı.

Kalp Atım Hızının Belirlenmesi: Sporcuların test sirasında, jogging süresince sergiledikleri KAH değerleri, göğüs üzerine yerleştirilen bir verici ve kolunda takılı olan telemetrik monitörler (Polar, Finland) aracılığı ile takip edildi.

Eklem Hareket Genişliği: Kalça fleksiyonu ölçümü ile eklem hareket genişliği belirlendi. Deneklerin kalça fleksiyonu ölçümleri ganiometre aleti ile gerçekleştirildi. Denekler sırt üstü pozisyonda düz bir zemin 
üzerine yatırılır. Bacaklar dik ve dizden bükülmeden yukarıya doğru kaldırılarak gerilir. Goniometre aleti femur başı (Greater Trachanter) merkez nokta alınarak yerleştirilir. Goniometrenin sabit kolu leğen kemiğinin üst kenarına (İlium Crest) ve Trochanter Majora doğru yerleştirilir. Hareketli kolu ise, femur kemiğine paralel bir şekilde ve (Lateral Condyle) kemiğine doğru yerleştirilir. Aktif esnetme yapılarak elde edilen açı derece cinsinden tespit edilir (Koçak ve ark., 2005). Yapılan ölçümler sağ ve sol olmak üzere iki taraftan alınarak iki ölçümün ortalaması değerlendirildi.

Dikey Siçrama ölçümü: Dikey sıçrama ölçümü TAKEI vertical meter markalı ölçüm aleti ile ölçüldü. Sporcular eller belde çift ayakla "matın üzerinde dizler 90 derece squatta olacak şekilde dururlarken sıçrayabildikleri kadar yukarı sıçradılar. Sıçrama 2 defa yapıldı en iyi derece üzerinden değerlendirildi.

30 metre sprint testi: Deneklerin $30 \mathrm{mt}$. Sprint süresi Newtest powertimer 300 cihazı ile ölçüldü. Denekler, başlangıç fotoselinin bir metre gerisinde bulunan başlangıç çizgisinden istediği zaman başladı. Ölçümler, 30 m'lik koşu mesafesinin başlangıç ve 30'uncu metrelerine yerleştirilen fotoseller ile yapıldı. 3'er dakikalık dinlenme aralıklarıyla iki kez ölçüm alındı ve iyi olan derece değerlendirildi.

\section{İstatistiksel Analiz}

Verilerin analizi SPSS 21 paket programı ile yapıldı. Verilerin normal dağılım gösterip göstermediği Kolmogorov-Smirnov testi ile bakılmış ve verilerin normal dağılım gösterdiği tespit edildi ( $p>0,05)$. Verilerin analizinde tekrarlı ölçümlerde tek yönlü varyans analizi (ANOVA) uygulanırken, farkın hangi koşuldan kaynaklandığının belirlenmesi için Bonferroni post hoc analizi uygulanmıştır. 


\section{Bulgular}

Tablo 1. Deneklerin Fiziksel Özellikleri

\begin{tabular}{lcccc}
\hline & $\overline{\mathrm{X}}$ & $\begin{array}{c}\text { Standart Sapma } \\
(\text { SS) }\end{array}$ & \multirow{2}{*}{ Minimum } & \multirow{2}{*}{ Maximum } \\
\hline Yaş (yıl) & 20,15 & 2,71 & 17,00 & 28,00 \\
Boy (cm) & 179,45 & 7,40 & 165,00 & 195,00 \\
VA (kg) & 75,20 & 9,90 & 59,00 & 92,00 \\
Spor Yaş1 (yıl) & 8,20 & 3,31 & 3,00 & 14,00 \\
\hline
\end{tabular}

Deneklerin fiziksel özellikleri tablo 1'de verildi.

Tablo 2. Deneklerin Isınma Protokollerine Göre Performans Değerleri

\begin{tabular}{|c|c|c|c|c|c|c|c|}
\hline & & $\bar{X}$ & SS & Median & $\min$ & $\max$ & $\mathrm{p}$ \\
\hline \multirow{3}{*}{$\begin{array}{l}\text { Kalça } \\
\text { Fleksiyon } \\
(\mathrm{cm})\end{array}$} & $\begin{array}{c}\text { Jogging } \\
\text { (a) }\end{array}$ & 105,25 & 11,17 & 105 & 85 & 125 & \multirow{3}{*}{$\begin{array}{c}0,032^{* *} \\
a<b, c\end{array}$} \\
\hline & $\begin{array}{l}\text { Dinamik } \\
\text { germe (b) }\end{array}$ & 116,50 & 10,27 & 115 & 100 & 135 & \\
\hline & $\begin{array}{c}\text { Statik } \\
\text { germe (c) }\end{array}$ & 118,32 & 12,45 & 117 & 102 & 137 & \\
\hline \multirow{3}{*}{$\begin{array}{l}\text { Siçrama } \\
\text { Yüksekliği } \\
(\mathrm{cm})\end{array}$} & $\begin{array}{l}\text { Jogging } \\
\text { (a) }\end{array}$ & 54,05 & 7,91 & 54 & 41 & 67 & \multirow{3}{*}{$\begin{array}{c}0,021^{* *} \\
c<a, b\end{array}$} \\
\hline & $\begin{array}{l}\text { Dinamik } \\
\text { germe (b) }\end{array}$ & 53,60 & 6,85 & 52 & 38 & 66 & \\
\hline & $\begin{array}{c}\text { Statik } \\
\text { germe }(\mathrm{c})\end{array}$ & 50,12 & 5,88 & 51 & 36 & 63 & \\
\hline \multirow{3}{*}{$\begin{array}{l}\text { 30m sprint } \\
\text { süresi (sn) }\end{array}$} & $\begin{array}{l}\text { Jogging } \\
\text { (a) }\end{array}$ & 4,54 & ,28 & 4,46 & 4,06 & 5,07 & \multirow{3}{*}{$\begin{array}{c}0,014^{* *} \\
c<a, b\end{array}$} \\
\hline & $\begin{array}{l}\text { Dinamik } \\
\text { germe }(b)\end{array}$ & 4,64 & ,36 & 4,52 & 4,16 & 5,62 & \\
\hline & $\begin{array}{c}\text { Statik } \\
\text { germe }(\mathrm{c})\end{array}$ & 4,80 & ,23 & 4,75 & 4,18 & 5,66 & \\
\hline
\end{tabular}

$\mathrm{p}<0,05$

\section{Tartışma}

Çalışmamızda uygulanan üç farklı 1sınma protokolünün, eklem hareket genişliğii, sıçrama yüksekliği ve sprint koşu performansı üzerindeki etkisini karşılaştırıldı. 
Kalça fleksiyon değerinin JD ve JS isınma protokolü sonrasında, J sonrasına göre daha yüksek olduğu tespit edildi. Bir eklemin uygun hareket genişliğine sahip olması, verimli hareket edebilme ile sportif ve günlük aktivitelerde düşük sakatlanma riski için oldukça önemlidir (akt. Çolak ve Çetin., 2010). Bu nedenle eklem hareket genişliğinin önemli olduğu spor branşlarında germe çalışmalarına önem verilmelidir.

Çalışmamızın bu bulgusunu destekleyen çalışmalara rastlanıldı. Bayanlara uygulanan dört farklı 1sınma çeşidinin eklem hareket genişliği ve esneklik üzerine etkisinin incelenmesi amacıyla yapılan bir çalışmada, etkin ısınma yönteminin germe egzersizleri ile yapılan ısınma protokolü olduğu tespit edilmiştir (Çolak ve Çetin, 2010). Williford ve ark. (1986) jogging ile yapılan ısınma sonrası yapılan streching hareketlerinin eklem esnekliğini arttırdığını belirtmişerdir. Fiziksel kondisyon dersine giren öğrencileri jog ve strech (JS), strech (S) ve kontrol grubu olarak üçe ayırmıştır. Ayak bileği esnekliğinin JS sonrasında $S$ ve $C$ sonrasına göre daha yüksek olduğunu belirtmişlerdir. Knight ve ark. (2001), yüzeysel ısınmanın, derin ısınmanın ve aktif ısınmanın plantar-flexor kaslar üzerindeki etkisini karşılaştırmışlardır. Test edilen yöntemler arasında ultrasonun gerilmeden 7 dakika önce kullanılması ayak bileği dorsifleksiyon hareket aralığının arttırılmasında en etkili olabileceğini belirtmişlerdir.

Çalışmamızda JS protokolü sonrası ölçülen dikey sıçrama yüksekliğinin J ve JD sonrasına göre daha düşük olduğu tespit edildi. Çalışmamızın bu bulgusunu destekler nitelikte çalışmalara rastlanıldı (Gelen, 2008; Faigenbaum et al., 2005; McNeal and Sands, 2001).

Statik germe ve dinamik tipte isınma egzersizinin dikey sıçrama performansına olan akut etkilerini ortaya koymak amacıyla yapılan bir çalişmada bizim bu bulgumuz ile örtüşen sonuçlar bulunmuş (Gelen, 2008). Isınma protokolleri, 5 dakika jogging ve 2 tekrar 15 saniye süreli 5 statik statik germe (Metod A), 5 dakika jogging ve 2 tekrar $15 \mathrm{~m}$. boyunca 12 dinamik tipte egzersiz (Metod B) ve son olarak sadece 5 dakika ısınma koşusundan (Metod C) oluşmuştur. Gelen'in (2008) araştırmanın bulgularına göre, düşük yoğunluklu aerobik nitelikli koşular sonrasında yapılan statik germe uygulamaları dikey sıçrama yüksekliğini negatif yönde, dinamik ısınma uygulamaları da pozitif yönde etkilemektedir. Cornwell ve ark. (2001) statik gerilmenin sıçrama yüksekliğini yaklaşık\% 4,4 oranında azalttığını bildirmiştir. 
Faigenbaum ve ark. (2005), statik esneme veya dinamik egzersiz performansı kullanarak 3 farklı ssınma protokolünün gençlerin fiziksel uygunluğu üzerindeki akut etkilerini incelemiştir. Isınma protokolleri, 5 dakikalık yürüme ve 5 dakikalık statik germe (SS), 10 dakikalık dinamik egzersiz (DY) veya 10 dakikalık dinamik egzersiz artı $15 \mathrm{~cm}$ 'lik kutulardan (DYJ) 3 drop sıçramadan oluşuyordu. Her isınma seansından sonra, denekler dikey sıçrama, uzun atlama, mekik koşusu ve v-sit esnekliği üzerinde test edildi. Verilerin analizi, SS'den sonra dikey sıçrama performansının DY ve DYJ ile karşılaştırıldığında önemli ölçüde düştüğünü ve uzun atlama performansının SS sonrasında DYJ ile karşılaştırıldığında önemli ölçüde azaldığını ortaya koydu.McNeal ve Sands (2001) jimnastikçilerle yaptıkları bir çalışmada, statik germenin sıçrama performansını $\% 9.6$ oranında azalttığını belirtmişlerdir.

Çalışmamızda $30 \mathrm{~m}$ sprint performansının ise JS protokolü ile ısınma gerçekleştirildiğinde, J ve JD protokolü ile isınmaya oranla daha düşük olduğu görüldü. Bizim çalışmamızın bu bulgusunu destekleyen çalışmalara rastlanılmıştır (Yıldız ve ark., 2013; Faigenbaum et al., 2005; Nelson ve ark, 2005b).

Faigenbaum ve ark. (2005) çalışmanın verilerinin analizinde mekik koşusu performansının, dinamik egzersize kıyasla statik gerilmeden sonra önemli ölçüde düştüğü ortaya çıkmıştır. Yıldız ve ark (2013) farklı sürelerde $(15,30$ ve $45 \mathrm{sn})$ uygulanan statik germenin sürat performans1na olan akut etkisinin incelemişlerdir. Bu araştırma düşük yoğunluklu aerobik egzersizi takiben, 15 sn süreli statik germe (SG15), 30 sn süreli statik germe (SG30), 45 sn süreli statik germe (SG45) ve sadece düşük yoğunluklu aerobik egzersiz (KU) (kontrol-hiç germe olmadan) yöntemlerinden oluşmaktaydı. Sporcular her protokolden sonra $20 \mathrm{~m}$ sürat testini gerçekleştirmişlerdir. Araştırmalarının sonuçları, alt ekstremiteye yönelik uygulanan statik germe uygulamalarının sporcuların sürat performanslarını düşürdügünü göstermektedir. Hatta statik germenin süresi arttıkça sürat performansının düştüğü gözlenmiştir. Fletcher ve Jones (2004) 20 m sürat performansı öncesinde uygulanan statik germenin sürat performansını düşürdüğünü bildirmişlerdir.

Fowles ve ark'1 (2000), 30 dakikalık pasif gerdirmenin, gerilmeden 5 dakika sonra motor ünitesinin aktivasyonunda önemli bir düşüşe ve 60 dakika boyunca devam eden kuvvette bir azalmaya neden olduğunu 
belirtmiştir. Sıçrama ve sprint hızının düşmesinin nedeni bu açıllama olabilir.

\section{Sonuç ve Öneriler}

Gerek dinamik gerek statik germe sonrası eklem hareket genişliğinin sade koşuya göre daha yüksek olduğu görüldü. Dolayısıyla eklem hareket genişliğinin önemli olduğu spor branşlarında hem sakatlanmayı en aza indirmek hem de yüksek performans sağlamak için mutlaka germe çalışmalarının yapılması gerekir. Ancak statik germeden hemen sonra sıçrama ve sprint performansı düşmektedir. Bunun önüne geçmek için ise bu tür aktivitelerden önce dinamik germenin yapılması önerilmektedir. 


\title{
EXTENDED ABSTRACT
}

\section{Effect of Different Warm-Up Protocols on Joint Range of Motion, Jumping and Sprint Performance}

\author{
Tülin Atan \\ Ondokuz Mayıs University
}

In warm-up exercises, the intensity and volume should be determined according to the individual characteristics of the athlete, their educational status, professionalism and training status. An intense warm-up time creates fatigue for athletes without training and adversely affects their work (Karabina et al., 2009). Despite the widespread use and acceptance of stretching exercises as the most important criterion before activities, the claimed benefits, which are on performance and on the prevention of injuries, have been the subject of debate in many studies. The study was carried out to investigate the effect of three different warming types on joint range of motion, jumping and sprint performance.

Thirty male students from the Faculty of Sport Sciences of Samsun Ondokuz Mayıs University participated in the study voluntarily. All athletes underwent three different warm-up protocols including jogging (J), jogging + dynamic stretching (JD) and jogging + static stretching (JS) exercises were applied to all athletes in random order on nonconsecutive days.

On the day of warming with Jogging (J), subjects ran for 10 minutes at an average heart rate of 120 beats / min and performed rest tests after 1 minute walk. Static stretching was performed slowly (active stretching), at a taut sensitivity point (pain threshold). Static stretching was performed for Hamstring, Quadriceps, Calf, Adductor and hip rotator muscle groups (Alter, 1988). After performing a 1 minute walk rest, performance tests were performed. In dynamic exercises consisting of 5 different movements, 1 movement lasted 1 minute. The movement started at the beginning of the $15 \mathrm{~m}$ line, the movement continued for $20 \mathrm{sec}-$ onds, the end of the line was reached and after resting the line for 10 
seconds, the same movement was repeated. After warm-up protocols; hip flexion, vertical jump test and 30 meter sprint test values were taken respectively. Repeated measures and post-hoc tests were used for statistical analysis.

Hip flexion value was found to be higher after JD and JS warming protocol compared to J. The proper range of motion of a joint is very important for efficient mobility and low risk of injury in sports and daily activities (act. Çolak and Çetin, 2010). Therefore, stretching studies should be given importance in sports branches where joint range of motion is important. There were studies supporting this finding of our study. Williford et al. (1986) evaluated the effects of warming the joints by jogging and then stretching on increases in joint flexibility. Subjects were 51 students enrolled in a physical conditioning class assigned to a jog and then stretch (JS), stretch and no jog (S), or a control group (C). They found a significant gain in ankle flexibility for the JS group compared to $S$ and $C$ groups. Knight et al. (2001) evaluated the effectiveness of superficial heat, deep heat, and active exercise warm-tip prior to stretching compared with stretching alone on the extensibility of the plantar-flexor muscles. Among the modalities tested, the use of ultrasound for 7 minutes prior to stretching may be the most effective for increasing ankle dorsiflexion range of motion.

In our study, the vertical jump height measured after JS protocol was found to be lower than after J and JD. There were studies supporting this finding of our study (Gelen, 2008; Faigenbaum et al., 2005; McNeal and Sands, 2001). Cornwell et al. (2001) reported that pre-event static stretching significantly reduced jump height by about $4.4 \%$. Faigenbaum et al. (2005) examined the acute effects on youth fitness of 3 different warm-up protocols utilizing static stretching or dynamic exercise performance. The warm-up protocols consisted of 5 minutes of walking and 5 minutes of static stretching (SS), 10 minutes of dynamic exercise (DY), or 10 minutes of dynamic exercise plus 3 drop jumps from $15-\mathrm{cm}$ boxes (DYJ). Following each warm-up session, subjects were tested on the vertical jump, long jump, shuttle run, and v-sit flexibility. Analysis of the data revealed that vertical-jump performance declined significantly following SS as compared to DY and DYJ, and long-jump performance was significantly reduced following SS as compared to DYJ. 
In our study, the sprint performance of $30 \mathrm{~m}$ after JS was found to be lower when compared with the J and JD protocol. Faigenbaum et al. (2005) study analysis of the data revealed that shuttle-run performance declined significantly following static stretching as compared to dynamic exercise. Fletcher and Jones (2004) reported that the static tension applied before $20 \mathrm{~m}$ speed performance decreases the speed performance.

As a result, it was observed that the range of motion of the joint after dynamic and static stretching was higher than plain running. Therefore, in sports branches where joint range of motion is important, stretching works must be performed both to minimize injury and to provide high performance. However, the jump and sprint performance decrease immediately after static stretching. In order to prevent this, dynamic stretching is recommended before such activities.

\section{Kaynakça / References}

Açıkada, C. ve Ergen, E. (1990). Bilim ve spor. Ankara: Büro-Tek Ofset Matbaacilık, 1. Baskı; 130.

Alter, M. J. (1988). Science of stretching. Champaign, IL: Human Kinetics.

Cornwell, A., Nelson, A.G., Heise, GD, Sidaway B. (2001). Acute effects of passive muscle stretching on vertical jump performance. J. Human Mov. Stud. 40, 307-324.

Çakıroğlu, M. (1997). Antrenman bilgisi. İstanbul: Şeker Matbaacılık, 2. Baskı; 69.

Çolak, M., ve Çetin, E. (2010). Bayanlara uygulanan farklı 1sınma protokollerinin eklem hareket genişliği ve esneklik üzerine etkileri. Fırat Üniversitesi Sağllk Bilimleri Tip Dergisi, 24(1), 001-008.

Çoknaz, H., Yıldırım, N.Ü., Özengin, N. (2008). Artistik cimnastikçilerde farklı germe sürelerinin performansa etkisi. Spormetre Beden Ĕ̆itimi ve Spor Bilimleri Dergisi, 6(3), 151-157.

Faigenbaum, A. D., Bellucci, M., Bernieri, A., Bakker, B., ve Hoorens, K. (2005). Acute effects of different warm-up protocols on fitness performance in children. The Journal of Strength \& Conditioning Research, 19(2), 376-381. 
Fletcher, I. M., ve Jones, B. (2004). The effect of different warm-up stretch protocols on 20 meter sprint performance in trained rugby union players. Journal of Strength and Conditioning Research, 18(4), 885-888.

Fowles, J., Sale, D., ve Macdougall, J. (2000). Reduced strength after passive stretch of the human plantarflexors. J. Appl. Physiol., 89, 1179-1188.

Fox, B. F.(1999). Beden eğitimi ve sporun fizyolojik temelleri (Çeviri: Cerit, M., ) Ankara: Bağırgan Yayımevi.

Gelen, E. (2008). Farklı ısınma protokollerinin sıçrama performansına akut etkileri. Spormetre Beden Ĕ̆itimi ve Spor Bilimleri Dergisi, 6(4), 207-212.

Karabina, F., Pirselimoğlu, E.T. (2017). Spor liseleri antrenman bilgisi ders kitabı. Ankara: MEB Devlet Kitabı, 1.baskı.

Knight, C.A., Rutledge, C.R., Cox, M.E., Acosta, M., ve Hall, S.J. (2001). Effect of superficial heat, deep heat, and active exercise warm-up on the extensibility of the plantar flexors. Phys Ther. 81, 1206-1214.

Koçak, M., Akkoyunlu, Y., ve Taşkın, H. (2005). 16-18 yaş grubu futbolcularda masajin esneklik üzerine etkisi. Spormetre Beden Eğitimi ve Spor Bilimleri Dergisi, 3(3), 105-109.

Mcneal, J., Sands W. (2003). Acute static stretching reduces lower extremity power in trained children. Pediatr. Exerc. Sci. 15, 139-145.

Nelson, A.G., Kokkonen, J., ve Arnall, D,A. (2005a). Acute muscle stretching inhibits muscle strength endurance performance. Journal of Strength and Conditioning Research, 19(2), 338-343.

Nelson, A. G., Driscoll, N.M., Landin, D.K., ve Young, M.A., Schexnayder, I.C. (2005b). Acute effects of passive muscle stretching on sprint performance. Journal of Sports Sciences, 23(5), 449-454.

Sevim, Y. (1997). Antrenman Bilgisi. Ankara:Tutibay Ltd. 29-109.

Williford, H.N., East, J.B., Smith, F.H., ve Burry, L.A. (1986). Evaluation of warm-up for improvement in flexibility. The American Journal of Sports Medicine, 14(4), 316-319.

Yıldız, S., Çilli, M., Gelen, E., ve Güzel, E. (2013). Farklı sürelerde uygulanan statik germenin sürat performansina akut etkisi. Journal of Human Sciences, 10(1), 1202-1213.

Ziyagil, M.A., Tamer, K., ve Zorba, E. (1994). Beden eğitimi ve sporda temel motorik özelliklerin ve esnekliğin geliştirilmesi. 1. Baskı, Ankara: Emel Matbaa, 36. 


\section{Kaynakça Bilgisi / Citation Information}

Atan, T. (2019). Farklı 1sınma protokollerinin eklem hareket genişliği, sıçrama ve sprint performansına etkisi. OPUS-Uluslararası Toplum Araştırmaları Dergisi, 13(19), 621-635. DOI: 10.26466/opus. 574260 